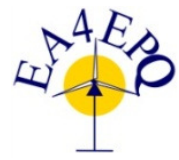

International Conference on Renewable Energies and Power Quality (ICREPQ'14) Cordoba (Spain), $8^{\text {th }}$ to $10^{\text {th }}$ April, 2014

Renewable Energy and Pourer Qualiuy. Fournal (RE\&PQJ)

ISSN 2172-038 X, No.12, April 2014

\title{
Comparison of Discharge Performance of 12V/150Ah Gel and AGM Sealed Lead- acid Batteries in Stand-alone PV-based Systems in UAE
}

\author{
Zahi M. Omer, Ahmed M. Alameri, Abbas A. Fardoun ${ }^{1}$, Ala A. Hussein ${ }^{2}$ \\ ${ }^{1}$ Electrical Engineering Department, United Arab Emirates University, P.O. Box 15551, Al-Ain, UAE. \\ Phone: +971-3-713-5145, Email: afardoun@uaeu.ac.ae \\ ${ }^{2}$ Electrical Engineering Department, United Arab Emirates University, P.O. Box 15551, Al-Ain, UAE. \\ Phone: +971-3-713-5332, Email: ala.hussein@uaeu.ac.ae
}

\begin{abstract}
This paper investigates the discharge performance of two major lead-acid batteries, namely $12 \mathrm{~V} / 150 \mathrm{Ah}$ Gel and AGM sealed lead-acid batteries, when operating in stand-alone (offgrid) mode in photovoltaic (PV) based systems in United Arab Emirates (UAE). At harsh environmental conditions such as in UAE where the temperature can go to extremely high level in the summer, the battery performance and replacement cost increases the concerns about the reliability and economic feasibility of those batteries. This paper compares the discharge characteristics of those batteries through discharge tests performed on four similar batteries (two of each type). Experimental results of the discharge tests followed by a comparison between the two batteries are presented in this paper.
\end{abstract}

\section{Key words}

Discharge capacity, discharge current, discharge efficiency, lead-acid battery, state-of-charge (SOC).

\section{Introduction}

Renewable energy technologies have been gaining great attention recently due to environmental issues such as the continuously increasing levels of $\mathrm{CO}_{2}$ emissions as well as strategic economic issues related to expected lack of fossil fuel. In UAE, the average solar radiation year round has one of the highest values in the world, [1]. In order to utilize the high solar radiation and to diverse the energy resources in UAE, which is among the highest priorities in the country, UAE has legislated many new policies recently to encourage the use of renewable energy sources such as solar power. Abu Dhabi's Economic Vision -2030 aims at generating $7 \%$ of Abu Dhabi energy requirements from renewable resources. In Dubai, it is projected to generate $1 \%$ of electricity needs from renewable sources by 2020 and $5 \%$ by 2030 .

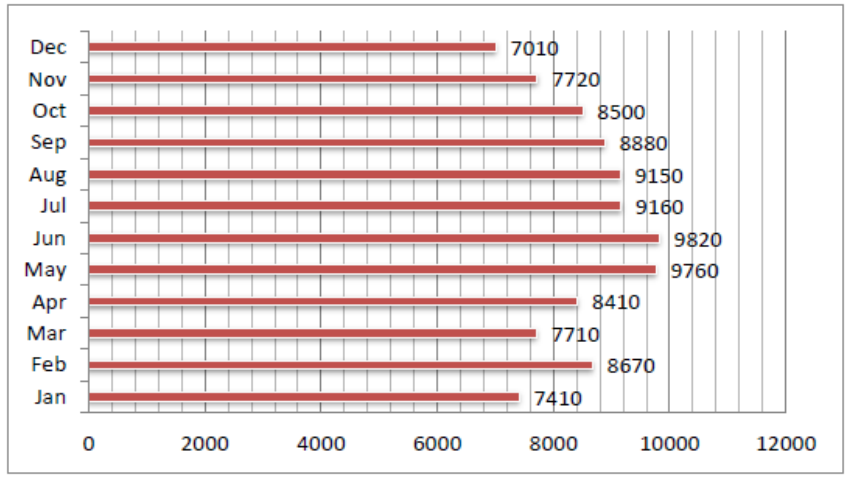

Fig. 1. Monthly solar radiation in in $\mathrm{kWh} / \mathrm{m}^{2}$ per day in UAE [1].

Due to the intermittent nature of renewable energy sources in general such as solar and wind sources, and due to the out-of-synchronization nature of those generation sources with the loads (generation peaks and peak loads are unsynchronized in general), energy storage devices such as batteries must be used to enhance the overall performance of renewable energy based systems. In general, energy storage can improve the performance of renewable energy sources by:

- Minimizing the fluctuation in the solar generated power.

- Supplying power in the absence of sunlight.

In fact, batteries are considered the backbone of solar PV off-grid systems. Among major rechargeable battery chemistries, lead-acid battery is the most mature technology and it is widely used in applications where cost is more important than space and weight, typically preferred as backup batteries for uninterruptable power supplies (UPS), alarm-systems, automobiles lighting and ignition as well as renewable energy systems applications. 
However, batteries are expensive and are the least reliable part of a renewable energy system. In addition, batteries usually reach their end-of-service life prematurely adding more concerns about their reliability and feasibility. The battery quality gets even worse in high temperature environments like UAE. Therefore, there is always room to improve the battery performance and reduce its cost.

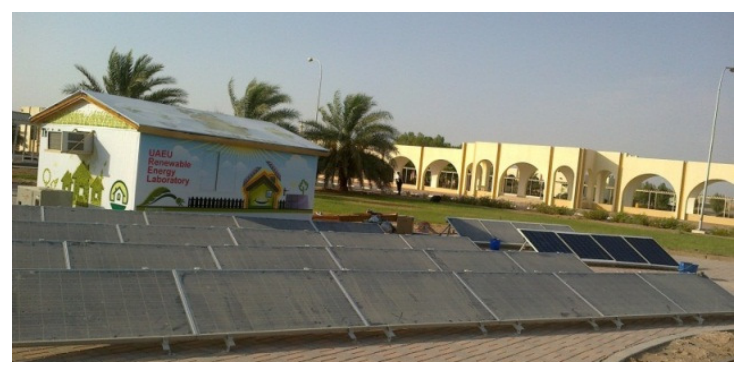

(a)

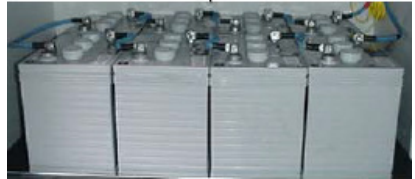

(b)

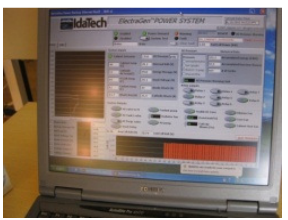

(c)
Fig. 2. Stand-alone PV system (renewable energy laboratory at UAE university) (a) $2 \mathrm{~kW}$ solar panels, (b) lead-acid backup batteries, and (c) graphical user interface (GUI) used for monitoring.

In this paper, the performance of two common types of lead-acid batteries used in stand-alone (off-grid) PV application (Figure 2) at UAE environmental conditions are tested and evaluated. Those batteries include 12V/150Ah Gel and AGM sealed lead-acid batteries (two of each type). The organization of this paper is as follows: Section 2 presents some aspects of battery operation and parameters. Section 3 includes discharge tests experimental results. Finally, summary and conclusions is given in Section 4.

\section{Battery Operation and Parameters}

To optimize the battery operation, each cell in the battery pack must be carefully monitored. The battery performance can be optimized by optimizing the charge/discharge process, ensuring that the battery doesn't exceed its design limits, and accurately estimating the internal parameters such as internal resistance and discharge capacity for each cell [2].

\section{A. Battery Operation}

The battery voltage, current, and temperature must be monitored all the time to ensure a reliable and safe operation. Each battery cell has a certain operating range that must not be exceeded as summarized in equations (1)(3).

$$
\begin{aligned}
& \mathrm{V}_{\text {cell,min }} \leq \mathrm{V}_{\text {cell }} \leq \mathrm{V}_{\text {cell,max }} \\
& \mathrm{T}_{\text {cell,min }} \leq \mathrm{T}_{\text {cell }} \leq \mathrm{T}_{\text {cell,max }}
\end{aligned}
$$

$$
\mathrm{SOC}_{\text {cell,min }} \leq \mathrm{SOC}_{\text {cell }} \leq \mathrm{SOC}_{\text {cell,max }}
$$

When the battery operates at outdoor condition, the prediction of its performance becomes more challenging. For example, when using traditional battery chargers, a rise in the battery temperature might be interpreted as if the battery is fully charged, while at outdoor conditions the rise in battery temperature can be a result of a rise in the ambient temperature. In addition, the capacity of the battery can vary significantly with the temperature. Therefore, the operation and parameters of the battery including the power capability, state-of-charge (SOC) and discharge capacity must be well understood in order to predict the battery performance at any condition.

As for battery charging, many techniques can be used to charge lead-acid batteries. In all the existing techniques, the battery performance such as the charging speed, rising temperature, efficiency, and battery cycle life can be improved [3]-[17]. For example, constant current/constant voltage $(\mathrm{CCCV})$ is a common technique that is used widely to charge lead-acid batteries. CCCV charging uses a constant current to charge the battery until its voltage reaches a certain limit, then the voltage is regulated until the current drops to a low level. Another technique called pulse charging uses a pulse current at a certain frequency to charge the battery. Other techniques such sinusoidal ripple charging uses a sinusoidal current with a DC shift. All those techniques differ from each other in term of charging efficiency, the heat they produce in the battery, and the charging time. However, in outdoor conditions, the charging profile cannot be controlled because of two reasons: 1) the solar power is uncontrollable, and 2) the solar power is not always available.

\section{B. State-of-Charge (SOC)}

The SOC is an indication of the amount of energy inside the battery compared to its maximum capacity. Mathematically, the SOC can be expressed in equation (4)

$$
\operatorname{SOC}(t)=\operatorname{SOC}(0)+\eta \int_{0}^{t} \frac{i(\tau)}{C_{T}} d \tau
$$

where $i(t)$ is the current as a function of time (positive for charging and negative for discharging), $C_{\mathrm{n}}$ is the nominal capacity (in $\mathrm{Ah}$ ), and $\eta$ is the (dis)charge efficiency.

It is important to accurately estimate the SOC of the battery to prevent premature end-of-life and ensure a reliable operation. The SOC must be estimated in real-time while the system is operating without interrupting its operation. This is impossible to achieve using conventional techniques such as the "discharge test", which cannot be used in real-time, or the "impedance spectroscopy", which requires an $\mathrm{AC}$ current injection into the cell to measure its impedance and is hard (if not impossible) to achieve dynamically. Other conventional techniques have their advantages and drawbacks; for example, "coulomb counting" is accurate and can be easily implemented for the first few cycles, but it can lead to drifting away after time 
and gives inaccurate results due to added errors. The "open circuit voltage" method is simple and accurate but requires very low current rates for a good accuracy. Kalman filters are very accurate and always converge to true SOC value, but they require a very accurate battery model and high computational capability. Artificial neural networks are robust and accurate but are expensive to implement, [18].

\section{Discharge Capacity}

The Discharge Capacity is an indication of the health of the battery (the Discharge Capacity is high for a new battery and low for an old battery). It is defined as the amount of energy a fully-charged battery can deliver before it is completely discharged. The Discharge Capacity can be calculated using equation (5):

$$
\text { Discharge Capacity }(\mathrm{Ah})=\int_{0}^{t_{\text {end }}} i_{\text {disch }}(t) \cdot d t
$$

where $i_{\text {disch }}(t)$ is the discharge current (in Amperes) as a function of time, $t$ is the time (in hours), and $t_{\text {end }}$ is the endof-discharge time (in hours).

Practically, the Discharge Capacity can vary significantly due to the variation of the following:

- Discharge current: As the discharge current increases, the losses inside the battery increases resulting in a reduction in the Discharge Capacity.

- Ambient temperature: At low temperatures, the resistivity of the electrolyte inside the battery is high. As a result, the discharge capacity is usually low at low temperatures. At high temperatures, discharge capacity is higher because of the low resistivity of the electrolyte at high temperatures. However, high temperatures can significantly reduce the lifetime of the battery, [19].

- Battery Life: It is an indication of the battery remaining life due to cycling (cycle-life) or aging (calendar-life). As the battery cyclic or calendar life increases, the discharge capacity decreases due to the degradation of the active materials inside the battery.

\section{Discharge Power}

The Discharge Power is another indication of the battery health. The Discharge Power is basically the amount of power the battery can deliver to the load at any instance. In general, a new battery has a higher power capability than an old battery. The amount of discharge power is calculated as follows:

$$
p_{\text {disch }}(t)=i_{\text {disch }}(t) \cdot v_{\text {disch }}(t)
$$

where $p_{\text {disch }}(t)$ is the discharge power (in Watts) as a function of time, and $v_{\text {disch }}(t)$ is the terminal voltage of the battery (in Volts).

\section{Experimental Results}

To compare the two batteries in terms of their discharge capacity, power and efficiency, the following test was performed on the four batteries:

1) Each battery was fully charged using CCCV profile.

2) Each battery was discharged with constant current of $\mathrm{C} / 2.5$ rate $(60 \mathrm{~A})$.

3) The electronic load was disconnected when the battery reached its lower cutoff voltage.

The lower cutoff voltages were obtained from the datasheet (10.5V for Gel and 10.8V for AGM). The test setup and discharge test results are shown in Figure 3 and Figure 4 (a)-(d), respectively.

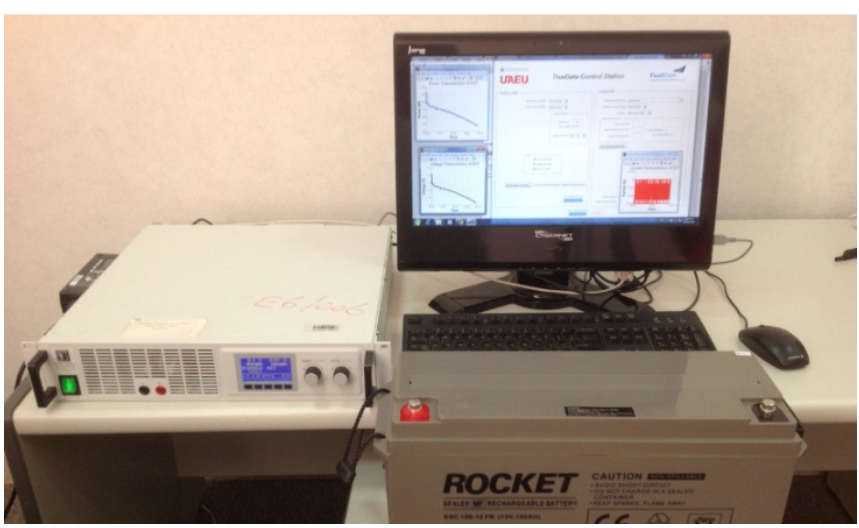

(a)

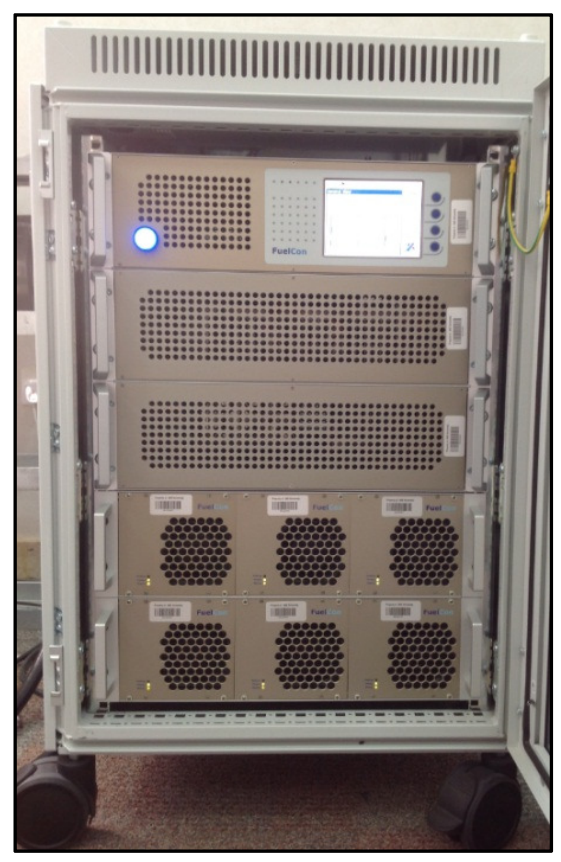

(b)

Fig. 3. Test setup (a) battery, power supply and PC, (b) 3kW FuelCon Electronic Load. 


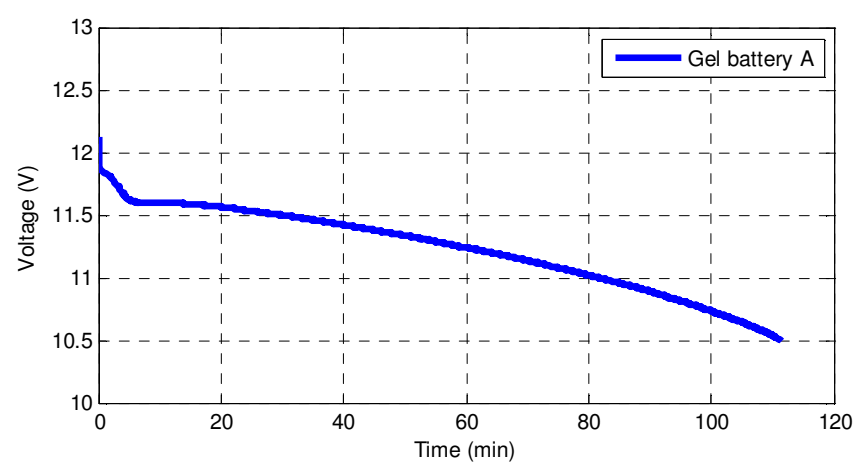

(a)

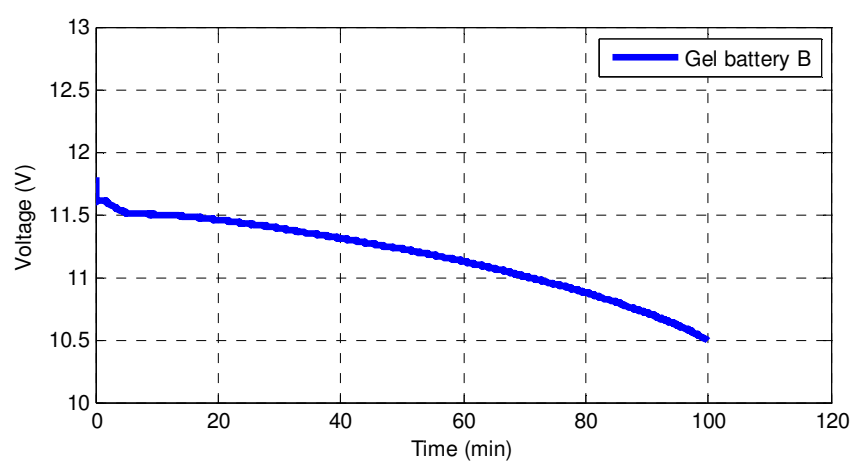

(b)

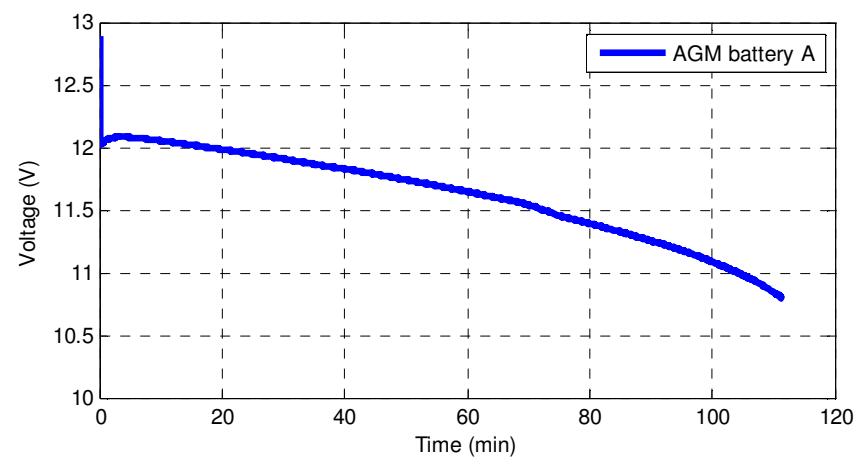

(c)

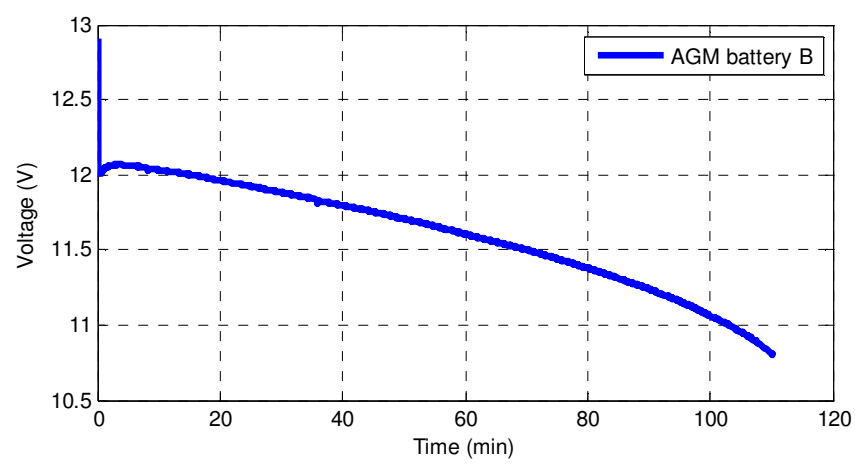

(d)

Fig. 4. Discharge characteristics of the tested batteries at $60 \mathrm{~A}$.
Table I compares the four batteries in terms of capacity, power and efficiency during a $60 \mathrm{~A}$ discharge test. The discharge efficiency was calculated using equation (7), where the nominal capacity that was used is 150Ah (from datasheet).

$$
\text { Disch. Efficiency }=\frac{\text { Disch. Capacity }}{\text { Nominal Capacity }}
$$

Table I. - Results of the 60A discharge test for the tested batteries.

\begin{tabular}{|c|c|c|c|c|}
\hline & $\begin{array}{l}\text { Gel } \\
\text { Battery A }\end{array}$ & $\begin{array}{l}\text { Gel } \\
\text { Battery B }\end{array}$ & $\begin{array}{l}\text { AGM } \\
\text { Battery A }\end{array}$ & $\begin{array}{l}\text { AGM } \\
\text { Battery B }\end{array}$ \\
\hline $\begin{array}{l}\text { Disch. } \\
\text { Capacity }\end{array}$ & $109 \mathrm{Ah}$ & $101 \mathrm{Ah}$ & $113 \mathrm{Ah}$ & $114 \mathrm{Ah}$ \\
\hline \multirow[t]{3}{*}{$\begin{array}{l}\text { Disch. } \\
\text { Power }\end{array}$} & $\begin{array}{l}693 \mathrm{~W} \\
(80 \% \text { SOC) }\end{array}$ & $\begin{array}{l}687 \mathrm{~W} \\
(80 \% \text { SOC })\end{array}$ & $\begin{array}{l}718 \mathrm{~W} \\
(80 \% \text { SOC) }\end{array}$ & $\begin{array}{l}717 \mathrm{~W} \\
(80 \% \text { SOC) }\end{array}$ \\
\hline & $\begin{array}{l}677 \mathrm{~W} \\
(50 \% \text { SOC })\end{array}$ & $\begin{array}{l}673 \mathrm{~W} \\
(50 \% \text { SOC })\end{array}$ & $\begin{array}{l}701 \mathrm{~W} \\
(50 \% \text { SOC) }\end{array}$ & $\begin{array}{l}699 \mathrm{~W} \\
(50 \% \text { SOC) }\end{array}$ \\
\hline & $\begin{array}{l}654 \mathrm{~W} \\
(20 \% \text { SOC })\end{array}$ & $\begin{array}{l}653 \mathrm{~W} \\
(20 \% \text { SOC })\end{array}$ & $\begin{array}{l}676 \mathrm{~W} \\
(20 \% \text { SOC) }\end{array}$ & $\begin{array}{l}676 \mathrm{~W} \\
(20 \% \text { SOC) }\end{array}$ \\
\hline $\begin{array}{l}\text { Disch. } \\
\text { Efficiency }\end{array}$ & $72.7 \%$ & $67.3 \%$ & $75.3 \%$ & $76 \%$ \\
\hline
\end{tabular}

\section{Summary and Conclusions}

This paper presented a comparison study between two lead-acid battery types (Gel and AGM batteries). All the tested batteries have $12 \mathrm{~V}$ nominal voltage and 150Ah nominal capacity and have almost the same condition (cyclic and calendar life). It was shown from the result that AGM batteries outperformed Gel batteries. In average, AGM batteries have higher discharge capacity, discharge power and discharge efficiency compared with Gel batteries by $8 \%, 3.6 \%$ and $8 \%$.

The results were obtained at pre-defined settings. However, the battery performance strongly depends on many factors such as the ambient temperature, discharge current, and battery condition. In general, the battery discharge capacity is strongly dependent on its operating temperature. At very low temperatures, the electrolyte may freeze, while at very high temperatures, the active materials may break down. At moderate temperatures, however, the battery performance as well as its capability to hold energy are optimal. Also, the results were obtained for battery packs that consist of multiple cells. Practically, the internal parameters and capacities will vary from one cell to another. In this case, the capacity of each individual cell must be monitored, and the total capacity of the battery pack will be limited by the cell with the lowest capacity.

The experimental work in this paper was performed on new batteries at a constant temperature and steady load. To extend the comparison, the effect of discharging current 
and temperature variation on the cycle-life must be considered.

\section{Acknowledgment}

This work was supported in part by the United Arab Emirates University, HTBM and ADWEA.

\section{References}

1. http://nawabi.de/power/solar/Abu\%20Dhabi\%20solar.asp.

2. A. A. Hussein and I. Batarseh "A Review of Charging Algorithms for Nickel and Lithium Battery Chargers", IEEE Transactions on Vehicular Technology, Volume 60, Issue 3, pp. 830-838, March, 2011.

3. L.R. Chen, J. J. Chen, CM. Ho, S.L. Wu, and D.T. Shieh "Improvement of Li-ion Battery Discharging Performance by Pulse and Sinusoidal Current Strategies", IEEE Trans. on Industrial Electronics, vol. 60, no. 12, December 2013.

4. L. R. Chen, "Design of duty-varied voltage pulse charger for improving Li-ion battery-charging response," IEEE Trans. Ind. Electron., vol. 56, no. 2, pp. 480-487, Feb. 2009.

5. L. R. Chen, N. Y. Chu, C. S. Wang, and R. H. Liang, "Design of a reflex-based bidirectional converter with the energy recovery function," IEEE Trans. Ind. Electron., vol. 55, no. 8, pp. 3022-3029, Aug. 2008.

6. C. H. Lin, C. Y. Hsie, and K. H. Chen, "A Li-ion battery charger with smooth control circuit and built-in resistance compensator for achieving stable and fast charging," IEEE Trans. Circuits Syst. I, Reg. Papers, vol. 57, no. 2, pp. 506517, Feb. 2010.

7. Y. H. Liu and Y. F. Luo, "Search for an optimal rapidcharging pattern for $\mathrm{Li}$-ion batteries using the Taguchi approach," IEEE Trans. Ind. Electron., vol. 57, no. 12, pp. 3963-3971, Dec. 2010.

8. Y. H. Liu, C. H. Hsieh, and Y. F. Luo, "Search for an optimal five-step charging pattern for Li-ion batteries using consecutive orthogonal arrays," IEEE Trans. Energy Convers., vol. 26, no. 2, pp. 654-661, Jun. 2011.

9. H. Qian, J. Zhang, J. S. Lai, and W. S. Yu, "A highefficiency grid-tie battery energy storage system," IEEE Trans. Power Electron., vol. 26, no. 3, pp. 886-896, Mar. 2011.

10. J. J. Chen, F. C. Yang, C. C. Lai, Y. S. Hwang, and R. G. Lee, "A high-efficiency multimode Li-ion battery charger with variable current source and controlling previous-stage supply voltage," IEEE Trans. Ind. Electron., vol. 56, no. 7, pp. 2469-2478, Jul. 2009.

11. L. R. Chen, J. J. Chen, N. Y. Chu, and G. Y. Han, "Currentpumped battery charger," IEEE Trans. Ind. Electron., vol. 55, no. 6, pp. 2482-2488, Jun. 2008.

12. L. R. Chen, R. C. Hsu, and C. S. Liu, "A design of a greypredicted Li-ion battery charge system," IEEE Trans. Ind. Electron., vol. 55, no. 10, pp. 3692-3701, Oct. 2008.

13. L. R. Chen, C. S. Liu, and J. J. Chen, "Improving phaselocked battery charger speed by using resistancecompensated technique," IEEE Trans. Ind. Electron., vol. 56, no. 4, pp. 1205-1211, Apr. 2009.

14. L. R. Chen, "A design of optimal pulse charge system by variable frequency technique," IEEE Trans. Ind. Electron., vol. 54, no. 1, pp. 398-405, Feb. 2007.

15. L. R. Chen, C. M. Young, N. Y. Chu, and C. S. Liu, "Phaselocked bidirectional converter with pulse charge function for
42-V/14-V dual voltage powernet," IEEE Trans. Ind. Electron., vol. 58, no. 5, pp. 2045-2048, May 2011.

16. J. Zhang, J. Yu, C. Cha, and H. Yang, "The effects of pulse charging on inner pressure and cycling characteristics of sealed Ni/MH batteries," J. Power Sources, vol. 136, no. 1, pp. 180-185, Sep. 2004.

17. L. R. Chen, S. L. Wu, D. T. Shieh, and T. R. Chen "SinusoidalRipple-Current Charging Strategy and Optimal Charging Frequency Study for Li-Ion Batteries", IEEE Trans. Ind. Electron., vol. 60, no. 1, pp. 88-97, January 2013.

18. A. A. Hussein, N. Kutkut, J. Shen and I. Batarseh "Distributed Battery Micro-storage Systems Design and Operation in a Deregulated Electricity Market", IEEE Transactions on Sustainable Energy, Volume 3, Issue 3, pp. 545556, July, 2012.

19. A. A. Hussein "Design and Operation of Stationary Distributed Battery Micro-storage Systems", Ph.D. Dissertation, University of Central Florida, Orlando, USA, July, 2011. 